\title{
Responses of football fans to relegation of their team from the English Premier League: PT S?
}

\author{
Philip Banyard, M ark Shevlin
}

Ir J Psych M ed 2001; 18(2): 66-67

\begin{abstract}
A bstract
0 bjectives: To measure the level of psychological distress caused to supporters of a football team by relegation from the English Premier League. The relationship between age, sex and psychological distress are examined.

M ethod: 0 pportunity sample cross-sectional survey. Participants were approached through networks of fans and through e-mail networks. Participants were supporters $(n=65)$ of two relegated premiership football teams. Participants completed the Impact of Event Scale.

Results: M ean total Impact of Event Scale scores indicated a clinically significant degree of psychological distress for the majority of respondents. A ge or sex of the participants did not predict Impact of Event Scale scores.

Conclusions: The results are discussed in terms of the magnitude of Impact of Event Scale scores in relation to other stressors. It is concluded that the impact of such sporting events is psychologically significant. The psychological literature has considered traumatic stress responses to a number of stressors such as threats to life, ${ }^{1}$ threats to psychological well-being, ${ }^{2}$ threats to physical/ psychological well-being of others, ${ }^{3}$ witnessing traumatic events $^{4}$ and involvement in a human or natural disaster. ${ }^{5,6,7}$
\end{abstract}

Keyw ords: Impact of Event Scale (IES); Trauma; Stress; Post Traumatic Stress; Football.

\section{Introduction}

$M$ ore recently it has been argued that people may expe rience severe psychological distress in response to events in which they are not participants or situations that pose no physical threat, for example the death of the Princess of Wales, ${ }^{8}$ and that would not meet the criteria established in the DSM -IV.

O ne aspect of modern living that appears to encourage strong emotional responses and behavioural displays of emotion is professional sport, for example Premier League football. A cademic interest in the behaviour and emotions of fans has generally centered around unacceptable aggressive displays. ${ }^{9-11}$ There is also, however, evidence that football games have an affect on social behaviours outside the sports arenas. For example, in the US the outcome of A merican football games has been shown to have an effect on the frequency of women admitted to emergency rooms

\footnotetext{
* Philip Banyard, Department of Social Sciences, Division of Psychology, The N ottingham Trent University, Burton Street, N ottingham, N G $14 \mathrm{BU}$, England.

M ark Shevlin, Department of Psychology and Communication, University of Ulster at M agee, BT 47 7J L, N orthern Ireland.

*Correspondence

SUBM ITTED: JULY 30, 1999. ACCEPTED: M ARCH 21, 2000.
}

following assault by males. ${ }^{12}$

The impact of football has been show $n$ to affect admission rates to medical facilities. $\mathrm{M}$ asterton and $\mathrm{M}$ ander ${ }^{13}$ found reductions in presentations of emergency psychiatric conditions during and after the Scotland football team's participation in World C up tournaments. In contrast, Steel ${ }^{14}$ found an increase in admission rates for selfpoisoning at a general hospital following a cup final defeat for a local team. Steels found that incidents of self-poisoning were less when the team were eliminated from the tournament at an earlier stage, therefore indicating that the level of distress may be affected by the importance of the game. A single game can have a substantial effect on football outcomes, for example a cup final, or a final game in a league season which determines which league the team will play in during the following season. It appears that there is a measurable response in football fans following these high-stake games.

This research examined the psychological response to relegation from the English Premier League by football supporters of two teams. The psychological effect of relegation was assessed using the Impact of Events Scale (IES). The IES was designed to assess the impact of any specific traumatic event. ${ }^{15}$ The scale is comprised of two subscales measuring intrusion and avoidance. The IES has been shown to have sound psychometric properties. Satisfactory estimates of test-retest reliability and internal consistency have been reported. ${ }^{15,16}$ In addition, evidence for a clear factor structure ${ }^{17}$ convergent validity ${ }^{18}$ and discriminant validity ${ }^{16}$ has been reported for the IES.

The aim of this study was to measure the psychological impact of relegation on team supporters and compare it with other stressors identified in the psychological literature. In addition the effect of age and sex on IES scores was examined.

\section{M ethod \\ Participants}

Participants were approached through supporter networks for two Premiership football clubs that had been relegated at the end of the the 1997/98 English football season. Completed Impact of Events Scale were e-mailed $(40 \%)$ or posted $(60 \%)$ to the authors. The total sample of 65 participants consisted of 44 males with mean age $30.26(S D=12.55)$ and 21 females with mean age 28.95 $(S D=13.64)$. The mean age for the entire sample was 29.80 (SD = 12.82).

$\mathrm{M}$ aterials

Each participant completed an IES within two weeks of the end of the 1997/98 English football season. Respondents were required to rate the frequency of intrusive thinking and avoidance tendencies since relegation. Researchers who have previously used the IES suggest that scores of 0-8 may be interpreted as subclinical, 9-25 as 
Table 1: Descriptive statistics for IES scores

\begin{tabular}{lccccc}
\hline IES Dimension & N & Mean & Min & Max & SD \\
Intrusion & 65 & 13.1 & 0.0 & 31.0 & 7.5 \\
Avoidance & 65 & 11.9 & 0.0 & 32.0 & 8.3 \\
Total & 65 & 25.0 & 0.0 & 51.0 & 14.1 \\
SD $=$ Standard deviation & & & & \\
\hline
\end{tabular}

Table 2: Percentages of IES scores as severity categories

\begin{tabular}{lcc}
\hline Category description & IES score & Percentage (\%) \\
Subclinical & $0-8$ & 14 \\
Mild & $9-25$ & 35 \\
Moderate & $26-43$ & 40 \\
Severe & $43-75$ & 11 \\
\hline
\end{tabular}

mild, 26-43 as moderate, and over 43 as severe, and that a score of 26 or over may be regarded as a "clinically significant reaction". ${ }^{19}$

\section{Results}

The IES was found to be internally consistent, with a Cronbach's alpha of 0.854 for the full scale. Slightly lower, but acceptable, estimates were found for the intrusion $(\mathrm{a}=$ 0.792 ) and avoidance $(a=0.765)$ subscales. A correlation of $0.61(p<0.05)$ was found between the scores the two subscales, consistent with the findings of R obbins and $\mathrm{H}$ unt, ${ }^{17}$ which indicates that the scale is measuring two related but relatively distinct dimensions.

Descriptive statistics for the IES scores are presented in Table 1. The percentages of total IES scores within each category of severity proposed by Shapiro ${ }^{19}$ are presented in Table 2. Using multiple regression neither age or sex were significant predictors of total IES scores $(F(2,62)=1.98, p>0.05)$.

\section{Discussion}

The mean total IES and subscale scores reported in Table 1 show that for this sample the responses are similar to those reported for events involving physical threats and natural disasters. Kopel and Friedman ${ }^{20}$ reported similar mean IES (24.4), intrusion (8.7) and avoidance (15.7) scores for South A frican police after exposure to violence. Johnsen et al ${ }^{21}$ reported mean IES (26.8), intrusion (13.2) and avoidance (13.6) scores for victims of an avalanche. Lower mean scores have been reported for firefighters. ${ }^{22}$

Therefore the mean scores in this study suggest that the psychological consequences of relegation can be significant. Further, in terms of classification, Table 2 indicates that over half the sample (51\%) are indicating responses that are clinically significant with $11 \%$ of these suffering severe psychological distress.

O verall, the results showed a high level of psychological distress as measured by the IES. This suggests that for supporters the psychological response to sporting events may not be trivial and is consistent with the findings of $\mathrm{M}$ asterton and $\mathrm{M}$ ander ${ }^{13}$ and Steel $\mathrm{S}^{14} \mathrm{M}$ oreover, the multiple regression indicated that IES scores were not related to any particular group in terms of sex or age. H ow ever, the results also indicate that such an extreme reaction to a sporting event was not evident for the entire sample, the variation in IES scores may reflect variation in the supporter's psychological investment in the fortunes of their club.
The fact that the sample was essentially self-selecting should not negate the substantive finding that the majority of the respondents were suffering significant psychological distress. Even if the sample represents individuals at the extreme of sporting involvement the percentage that showed signs of psychological distress represents a significant amount of people in terms of the entire football supporting population. Further it is difficult to argue that the responses were artifacts of the measurement instrument. The IES has been demonstrated to have sound psychometric properties and is used extensively in the trauma literature. ${ }^{23}$

In conclusion, this study suggests that stressors or events that would not meet the clinical criteria for traumatic stress can, if only temporally, induce high levels of psychological distress. Other behavioural indicators of distress among the supporters of relegated teams may be expected such as sickness from work, reduced productivity, declining sales of local and national newspapers, and increased admission to hospital with self-injury. Further research could examine the effects of the recency of the event in relation to the level of distress, and determine if the findings of this study are consistent across other sporting events both at a national and international context.

\section{References}

1. Cella DF, M ahon SM , D onovan M I. Cancer recurrence as a traumatic event. Behav $M$ ed 1990; 16: 15-22.

2. A mick-M CM ullan A, Kilpatrick DG, Veronen LJ, Smith S. Family survivors of homicide victims: theoretical perspectives and an exploratory study. J Traumatic Stress 1989; 2: 21-35.

3. Fullerton CS, Ursano RJ. Posttraumatic responses in spouse/significant others of disaster workers. In: Fullerton CS, U rsano RJ (eds). Postraumatic stress disorder: acute and long-term responses to trauma and disaster. Washington: A merican Psychiatric Press, 1997; 59-75.

4. H erlofsen P. G roup reactions to trauma: An avalanche accident. In: Ursano RJ, M CCaughy BG, Fullerton CS (eds). Individual and community responses to trauma and disaster: The structure of human chaos. Cambridge: Cambridge University Press, 1994; 248-66.

5. M CFarlane AC. The aetiology of post-traumatic morbidity: predisposing, precipitating and perpetuating factors. Br J Psychiat 1989; 154: 221-8.

6 . H odgkinson PE, Stewart M. Coping with catastrophe: a handbook of disaster management. London: Routledge, 1991.

7. Curle CE, Williams C. Post-traumatic stress reactions in children: $G$ ender differences in the incidence of trauma reactions at two years and examination of factors influencing adjustment. Br J Clin Psychol 1996; 35: 297-309.

8. Shevlin M, Brunsden V, Walker S, Davies M, Ramkalawan T. Her death and funeral rate as traumatic stressors. BM J 1997; 315: 1467-8.

9. $M$ arsh $P$, R osser E, H arré R. The rules of disorder. London: R outledge, 1978. 10. M urphy P, W illiams J, D unning E. Football on Trial: Spectator violence and development in the football world. London: Routledge, 1990.

11. Russell GW Goldstein JH. Personality differences between Dutch football fans and nonfans. Soc Behav Personality 1995; 23: 199-204.

12. White G F, Katz J, Scarborough KE. The impact of professional football games upon violent assaults on women. Violence and Victims 1992; 7: 157-71. 13. $M$ asterton G, M ander AJ. Psychiatric emergencies, Scotland and the World Cup finals. Br J Psychiat 1990; 156: 475-8.

14. Steels M D. Deliberate self poisoning - $\mathrm{N}$ ottingham Forest Football $\mathrm{Club}$ and FA Cup defeat. Ir J Psych M ed 1994; 11: 76-8.

15. H orowitz M J, W ilner N, Alvarez W. Impact of Events Scale: A measure of subjective stress. Psychosomatic M ed 1979; 41: 209-18.

16. Zilberg N J, Weiss DS, H orowitz M J. Impact of Event Scale: A cross validation study and some empirical evidence supporting a conceptual model of stress response syndromes. J Con Clin Psychol 1982; 50: 407-14.

17. Robbins I, H unt N. Validation of the IES as a measure of the long-term impact of war trauma. Br J H ealth Psychol 1996; 1: 87-9.

18. N eal LA, Busuttil W, Rollins J, H erepath R, Strike P, Turnball G. Convergent validity of measures of post-traumatic stress disorder in a mixed military and civilian population. I T raumatic Stress 1994; 7: 447-55.

19. Shapiro F. EM DR: Level 1 training manual. Pacific Grove: CA, 1996

20. Kopel H, Friedman M. Posttraumatic symptoms in South A frican police exposed to violence. J Traumatic Stress 1997; 10, 307-317.

21. Johnsen BH, Eid J, Løvstad T, M ichelsen LT. Post-traumatic stress symptoms in nonexposed, victims, and spontaneous rescuers after an avalanche. J Traumatic Stress 1997; 10: 133-140.

22. M CFarlane AC. A voidance and intrusion in posttraumatic stress disorder. J 22. M CFarlane AC. A voidance and intrusion

23. Weiss D S, M armar CR. The Impact of Event Scale - R evised. In: Wilson JP, Keane TM (eds.) Assessing psychological trauma and PT SD. N ew York, NY, USA: Guilford Press, 1997; 399-411.

26. Wilson JP. The historical evolution of PT SD diagnostic criteria: from Freud to DSM -IV.J Traumatic Stress 1994; 7: 681-98.

24. American Psychiatric A ssociation. Diagnostic and Statistical M anual of $M$ ental Disorders, 3rd edition. W ashington, DC: APA, 1987.

25. A merican Psychiatric A ssociation. Diagnostic and Statistical M anual of $M$ ental Disorders, 4th edition. W ashington, DC: APA, 1994. 